\title{
On the Relationship between Speech Acts and Psychological States
}

\begin{abstract}
This paper defends a theory of speech act that I call concurrentism. It consists of the following three theses. 1. We believe, ceteris paribus, that other people's speech acts concur with their beliefs. 2. Our speech acts, ceteris paribus, concur with our beliefs. 3. When our speech acts deviate from our beliefs, we do not, ceteris paribus, declare the deviations to other people. Concurrentism sheds light on what the hearer believes when he hears an indicative sentence, what the speaker believes when he says an indicative sentence, what the speaker does after he says an indicative sentence contrary to what he believes, why Moore's paradox occurs, why it is puzzling to say some variants of Moorean sentences, and why it is not absurd to say other variants of Moorean sentences.
\end{abstract}

\section{Keywords}

Default Belief, Default Desire, Moorean Sentence, Moore's Paradox, Speech Act

Seungbae Park

Division of General Studies

Ulsan National Institute of Science and Technology

Ulju-gun, Ulsan 689-798

Republic of Korea

Email: nature@unist.ac.kr

\section{Introduction}

A speech act is a complicated affair involving a speaker and a hearer. When the speaker says an indicative sentence to the hearer, something goes on in the speaker's mind and in the hearer's mind. This paper aims to shed light on how our speech acts are related to our psychological states, such as beliefs and desires. In Section 2, I will develop a theory of speech act that I call concurrentism, and then show that it receives support from a psychological study and goes well with evolutionary theory. In Section 3, I will apply it to Moore's paradox and the diverse variants of Moorean sentences. It will become clear that other things being equal, we believe that other people speak as they believe, and we speak in accordance with what we believe. It will also become clear that after we speak contrary to what we believe, we keep to ourselves the discrepancy between what we speak and what we believe, ceteris paribus.

\section{Concurrentism}

We usually believe that other people speak in accordance with what they believe. For example, I ask my friend what time it is. He takes a look at his watch, and he tells me, "It's 12 o'clock." I believe that he says so because he believes that it is 12 o'clock. Imagine, however, that I once told my friend a lie about the time, he missed his train, he has a strong desire to take revenge on me, and I know that his desire to take revenge on me is stronger than his desire to speak honestly to me about the time. In such a case, I do not believe that he speaks as he believes.

This example suggests that we have the doxastic inclination that we believe, ceteris paribus, that other people speak in accordance with what they believe, i.e., other things being equal, we believe that other people speak as they believe. In other words, we have the default belief that what other people speak agrees with what they believe. The default belief is the 
belief that we have unless we have a special belief defeating it in a particular social context. Thus, we believe that other people's speech act matches up with their doxastic state in the absence of the better special belief, and that other people's speech act deviates from their doxastic state in the presence of the better special belief.

We usually speak in accordance with what we believe. For example, my friend asks me what time it is. I take a look at my watch. I believe that it is 12 o'clock. So I tell my friend, "It's 12 o'clock." Imagine, however, that my friend once told me a lie about the time, I missed my train, I have a strong desire to take revenge on him, and the desire is stronger than the desire to speak honestly to him. In such a case, I speak dishonestly to him, and what I speak diverges from what I believe.

This example suggests that we have the linguistic inclination that we speak, ceteris paribus, in accordance with what we believe, i.e., other things being equal, we speak as we believe. To put differently, we have the default desire to speak in accordance with what we believe. The default desire is the desire that we have unless we have a special desire defeating it in a particular social context. Thus, our speech act matches up with our doxastic state in the absence of the stronger special desire, and does not match up with our doxastic state in the presence of the stronger special desire.

Let me now turn to a psychological study indicating how our speech acts are related to our psychological states. Leon Festinger and James Carlsmith (1959) contend that when we speak contrary to what we believe, we feel a kind of psychological discomfort called cognitive dissonance, and then we replace an old belief with a new belief so that our doxastic state may be in line with what we say, thereby achieving a kind of psychological comfort called cognitive consonance:

If a person is induced to do or say something which is contrary to his private opinion, there will be a tendency for him to change his opinion so as to bring it into correspondence with what he has done or said. (Festinger and Carlsmith, 1959: 209)

Suppose, for example, that you performed a tedious task, and you believe that the task was tedious. You are, however, offered a monetary reward on condition that you say to the experimenter that the task was interesting. You say to the experimenter that the task was interesting, and you go through cognitive dissonance. The conflict between what you said and what you believe causes the psychological discomfort. Afterwards, however, you persuade yourself that the task was interesting, and then return to cognitive consonance.

Let me make two comments about the preceding psychological study. First, the observation that we suffer from cognitive dissonance when we speak contrary to what we believe goes hand in hand with the linguistic inclination that we speak, ceteris paribus, in accordance with what we believe. Second, it is noteworthy that in the psychological experiment, no subject said to the experimenter, "Frankly speaking, the task was tedious, but I said to you it was interesting because I wanted to make money." The subjects rather endured the cognitive dissonance and then changed their beliefs. Thus, the study suggests that we have the inclination to conceal the embarrassing truth that there is discrepancy between what we speak and what we believe.

Let me now turn to the ethical issue concerning our speech acts and doxastic states. I argue elsewhere (2015a: 224-226) that our speech act might be unethical if it does not match up with our doxastic state. Imagine, for example, that there is a successful televangelist. He persuaded millions of television viewers into Christianity. It later turns out, however, that he is a thorough atheist. He just spoke as if he were a theist. He said, for example, "God loves 
you," although he did not believe that God exists. His speech acts did not match up with doxastic states! In such circumstances, the converted would feel that they were deceived, and that his speech acts were unethical. To use the concurrentist terms, the televangelist went against the linguistic inclination that we speak, ceteris paribus, as we believe. This example suggests that the discrepancy between speech acts and doxastic states incurs moral blames in certain social contexts.

The psychological study and the example of the televangelist indicate under what condition we are allowed to declare that there is a discrepancy between what we speak and what we believe. The condition is that we know that the revelation of the discrepancy is not embarrassing and does not incur a moral blame to us. Once this condition is met, we are free to lay bare the discrepancy between what we speak and what we believe. If this condition is not satisfied, however, we are inclined to keep the discrepancy to ourselves. Thus, we have another linguistic inclination that after we speak contrary to what we believe, we do not, ceteris paribus, declare to other people that there is a discrepancy between what we speak and what we believe.

So far I introduced one doxastic inclination and two linguistic inclinations in connection with our speech acts and our psychological states. The inclinations kick in when we hear an indicative sentence, when we speak an indicative sentence, and when we speak contrary to what we believe. They are put as follows:

(D) We believe, ceteris paribus, that other people speak as they believe.

(L1) We speak, ceteris paribus, as we believe.

(L2) After we speak contrary to what we believe, we keep to ourselves, ceteris paribus, the discrepancy between what we speak and what we believe.

(D), (L1), and (L2) jointly constitute what I call concurrentism. Simply put, concurrentism states that we usually believe that other people's speech acts concur with their beliefs, our speech acts usually concur with our beliefs, and when our speech acts deviate from our beliefs, we usually do not broadcast the deviations to other people. By keeping the deviations to ourselves, we give the impression that our speech acts concur with our belief.

An evolutionary explanation can be given of why we have the inclinations, (D) and (L1). It is a platitude in evolutionary biology that cooperation increases the chance that a group of organisms perpetuates itself. Imagine that there were two groups of organisms. The members of one group had the default belief that others speak as they believed and the default desire to speak as they believed, whereas the members of the other group did not. So there was more cooperation in the first group than in the second group, and the first group defeated the second group in the competition to survive and reproduce. We have the default belief and the default desire because we inherited the genes responsible for the psychological traits from our ancestors. Our ancestors did better in terms of survival and reproduction than their competitors who did not have the psychological traits. Thus, evolutionary theory explains why we have the inclinations, (D) and (L1).

An evolutionary explanation can also be given of why we have the inclination, (L2). It is also a platitude in evolutionary biology that there are cheaters in nature, organisms that take advantage of other organisms. Such organisms exist today because the inclination to deceive competitors increases the probability that organisms survive and reproduce. Imagine that there were two kinds of individuals in a group. The first kind of individuals had the inclination to keep to themselves the discrepancy between what they spoke and what they believed, whereas the second kind of individuals did not. It is clear that the former had a 
better chance to survive and reproduce than the latter. The former could tell a lie in a consistent manner. So they could take advantage of their competitors. In contrast, the latter could not tell a lie in a consistent manner. After telling a lie, they said frankly to their competitors about what they believed. So they could not take advantage of their competitors. We have the inclination to keep to ourselves the discrepancy between what we speak and what we believe because we inherited genes responsible for the inclination from our ancestors. Our ancestors were engaged in the relentless battle to deceive others and to avoid being deceived. The psychological property enabled our ancestors to defeat their competitors who did not have it. Thus, evolutionary theory also explains why we have the inclination, (L2). It is for such reason that Elliott Sober says that within "each population, individual selection favors selfishness over altruism" (1993: 98).

Concurrentism is intuitive and meshes well with evolutionary theory. What is the point of belaboring the obvious theory? Concurrentism, although obvious, would be rejected by many eminent philosophers, such as Henry Price (1969), Willard V. O. Quine (1960), Gilbert Ryle (1949), Richard Braithwaite (1932-1933), Ruth Marcus (1990), L. Jonathan Cohen (1992), Eric Schwitzgebel (2001, 2002), Robert Stalnaker (1984), Frank Ramsey (1931), Daniel Dennett (1978), Charles Travis (2003), Robert Audi (1994), Lyn Baker (1995), and Danielle Bromwich (2010). These philosophers contend that, for example, when I ask you the time, you say, "It's 12 o'clock" not because you have the default desire to speak in accordance with what you believe but because you believe that it is 12 o'clock. Your belief that it is 12 o'clock has the disposition to answer my question honestly, and the belief alone is enough to explain why you answered my question as you did. Thus, as far as these philosophers are concerned, it is otiose to postulate the existence of the default desire to speak as we believe. I criticize their theory of speech act elsewhere (Park, 2015b). In addition, I am doubtful that their theory of speech act can account for Moore's paradox and the variants of Moorean sentences. This issue, however, should be picked up in a separate paper. The present paper focuses on defending concurrentism rather than on criticizing its rival theory.

If concurrentism is the true theory of how our speech acts are related to our psychological states, it should be able to account for Moore's paradox and the variants of Moorean sentences. The next section aims to explain them in terms of concurrentism.

\section{Applications}

\subsection{Moore's Paradox}

What is Moore's paradox? It was first discovered by G. E. Moore (1944). It occurs when we say a sentence of the form 'P, but I do not believe that $\mathrm{p}$ ', or when we say a sentence of the form 'P, but I believe that not p.' It occurs, for example, when I say, 'It's raining, but I don't believe it's raining," or when I say, "It's raining, but I believe it's not raining." A sentence of the first form is called an omissive Moorean sentence, and a sentence of the second form is called a commissive Moorean sentence in the literature. The idea is that when we say, "It's raining, but I don't believe it's raining," our belief system omits the true belief that it is raining, and when we say, "It's raining, but I believe it's not raining," our belief system is committed to the false belief that it is not raining.

Moore's paradox occurs not only when we say a Moorean sentence but also when we believe a Moorean sentence. It occurs, for example, when I silently believe the sentence 'It is raining, but I do not believe that it is raining.' Speaking a sentence is a speech act which occurs in connection with other people. In contrast, believing a sentence is a mental act which can occur independently of other people. So a speech act is a public affair, whereas a mental 
act is a private affair. This paper aims to defend a linguistic theory of speech acts, not an epistemological theory of doxastic states. So it concerns Moore's paradox that occurs in our speech acts, but not in our minds.

An interesting challenge to theoreticians is to illuminate why it is puzzling to say a Moorean sentence. Philosophers believe that contradiction is at the heart of the absurdity of saying a Moorean sentence, but it is not obvious wherein contradiction lies. The first conjunct 'It is raining' does not contradict the second conjunct 'I do not believe that it is raining.' After all, the two conjuncts are compatible with each other, i.e., they can both be true. The first conjunct contradicts a third sentence 'It is not raining', and the second conjunct contradicts a fourth sentence 'I believe that it is raining.' But these two conjunctions have the form: $\mathrm{p}$, but not $\mathrm{p}$. Accordingly, they are not Moorean sentences.

According to concurrentism, Moore's paradox can be explained in terms of the aforementioned three inclinations: (D), (L1), and (L2). When the speaker says, "It's raining, but I don't believe it's raining," the first conjunct prompts the hearer to believe that the speaker believes that it is raining. The hearer's default belief contradicts the second conjunct that the speaker does not believe that it is raining. In addition, when the speaker says the first conjunct 'It's raining,' he goes against the linguistic inclination, (L1), that we speak, ceteris paribus, as we believe. When the speaker says the second conjunct 'I don't believe it's raining,' he goes against the linguistic inclination, (L2), that we do not, ceteris paribus, declare to other people that there is a discrepancy between what we speak and what we believe. So he owes the hearer the following two explanations. First, he needs to explain why he says, "It's raining," when he does not believe that it is raining. In other words, he needs to tell the hearer what the special desire is that is stronger than the default desire to say, "It's not raining." Second, he needs to explain why he says, "I don't believe it's raining," thereby revealing the embarrassing truth that his assertion of the first conjunct goes contrary to what he believes. In other words, he needs to tell the hearer what makes him think that the revelation of the discrepancy is not embarrassing and does not incur a moral blame to him. In sum, the contradiction between the hearer's default belief and the speaker's second conjunct, the violation of (L1), and the violation of (L2) jointly contribute to the absurdity of the Moorean sentence.

Concurrentism implies that it is not absurd to say a Moorean sentence in certain social contexts. Let me give such an example. Imagine that Galileo was tried in court for holding the secular view that the earth moves around the sun. The prosecution offered him a deal that if he spoke in court that the earth was at rest, he would be exonerated. Afraid of being sent to jail, he spoke in court, "The earth is at rest." After saying so, however, he said to his students and followers nearby, "But I don't believe the earth is at rest." His students and followers heard his entire Moorean sentence, 'The earth is at rest, but I don't believe the earth is at rest.' His Moorean sentence, however, was not puzzling to them. Why was it not perplexing to them?

Concurrentism offers the following two reasons. First, Galileo had the desire to avoid the persecution, and the special desire was stronger than the default desire to speak as he believed. Second, it was obvious to his students and followers why he said the first conjunct and the second conjunct. They knew that he said, "The earth is at rest," because he wanted to avoid the persecution, and that he said, "I don't believe the earth is at rest," because he had the default desire to speak as he believed and because he wanted to assure them that his belief about the earth did not change. In addition, Galileo knew that the revelation of the discrepancy between his speech act and his doxastic state to his students and followers would not be embarrassing and would not incur a moral blame to him. So he did not owe his hearers 
an explanation of why he laid bare to them the discrepancy between his speech act and his doxastic state. For these two reasons, his Moorean sentence was not absurd to them.

Imagine now that a beggar entered the court room the moment Galileo said, "The earth is at rest." The beggar did not know who the defendant was, why the defendant was tried, and why the defendant said, "The earth is at rest." But he also heard the defendant saying to some audience, "But I don't believe the earth is at rest." So he heard Galileo's entire Moorean sentence 'The earth is at rest, but I don't believe the earth is at rest.' As far as the beggar was concerned, Moore's paradox occurred. Galileo's Moorean sentence sounded strange to him because his default belief that the defendant believed that the earth was at rest contradicted the second conjunct, and because he had no idea why the defendant said the first conjunct when he did not believe that the earth is at rest, and why he disclosed to some audience that his speech act did not match up with his doxastic state.

This example shows that the speaker's knowledge state and the hearer's knowledge state determine whether a Moorean sentence sounds puzzling or not, i.e., whether Moore's paradox occurs or not. A Moorean sentence is not queer to the hearer, if the hearer knows that the speaker has the special desire that defeats the default desire to say as he believes, and if the speaker and the hearer know that disclosing the discrepancy between his speech act and his doxastic state is not embarrassing and does not incur a moral blame to the speaker. In contrast, a Moorean sentence is queer to the hearer, if the speaker and the hearer do not have the foregoing knowledge. Thus, the Moorean sentence is reasonable or unreasonable, depending on whether the speaker and the hearer have the relevant knowledge or not.

\subsection{Variants of Moore's Paradox}

Concurrentism can handle not only Moore's paradox but also several variants of Moorean sentences. As John Williams (2013: 2459) notes, it is irrational to say a variant of a Moorean sentence 'It's raining, but no one believes it's raining.' Why is it irrational to say such a sentence? Concurrentism answers that the first conjunct prompts the hearer to believe that the speaker believes that it is raining. The hearer's default belief entails that there is one person, viz., the speaker, who believes that it is raining. This logical consequence of the hearer's default belief contradicts the second conjunct that no one believes that it is raining. Furthermore, the speaker goes against (L1) and (L2). So the speaker owes the hearer the explication of what the special desire is that defeats the default desire to speak as he believes, and the explication of what makes him think that the revelation of the discrepancy between his speech act and his doxastic state is not embarrassing and does not incur a moral blame to him. In the absence of the explications, the hearer's puzzlement persists.

It is not absurd, Moore (1993: 208) notes, to say a variant of a Moorean sentence 'It's raining, but he doesn't believe it's raining.' Why is it not odd to say such a sentence? According to concurrentism, the first conjunct 'It's raining' causes the hearer to believe that the speaker believes that it is raining. The hearer's default belief does not contradict the second conjunct that a third person does not believe that it is raining. Moreover, there is no reason for thinking that the speaker goes against (L1) and (L2). It is not surprising that this variant of the Moorean sentence does not perplex the hearer.

It is not absurd, Moore (1993: 208) also observes, to say a variant of a Moorean sentence 'It was raining, but I did not believe that it was raining.' Why is such a sentence not puzzling? Concurrentism answers that the first conjunct 'It was raining' prompts the hearer to believe not that the speaker believed but that the speaker believes that it was raining. The hearer's default belief does not contradict the second conjunct that the speaker did not believe that it was raining. It is not a contradiction that the speaker believes that it was raining, and 
that the speaker did not believe that it was raining. After all, the first conjunct of this conjunction is a description of the speaker's present doxastic state, whereas the second conjunct is a description of the speaker's past doxastic state, and mental states change as time goes. Furthermore, as in the previous example, there is no reason for thinking that the speaker goes against (L1) and (L2). It is not surprising that this variant of the Moorean sentence is not puzzling to the hearer.

\subsection{Commissive Moorean Sentences}

All the examples I discussed so far are omissive Moorean sentences and the variants thereof. Let me now turn to commissive Moorean sentences and the variants thereof. Recall that a commissive Moorean sentence has the form 'P, but I believe that not p.' Suppose that the speaker says, "It's raining, but I believe it's not raining." Moore's paradox has arisen. Concurrentism says that the first conjunct causes the hearer to believe that the speaker believes that it is raining. The second conjunct, on the other hand, says that the speaker believes that it is not raining. It is a contradiction that it is raining, and it is not raining. So contradiction occurred between what the hearer takes to be the speaker's belief and what the second conjunct claims to be the speaker's belief. As in the case of an omissive Moorean sentence, the speaker goes against (L1) and (L2). As a result, his commissive Moorean sentence is absurd.

If the preceding analysis is correct, concurrentism should also be able to accommodate the following example. Imagine again that Galileo was tried in court for the religious reason. He said in court, "The earth is at rest." After saying so, however, he said to his students and followers nearby, "But I believe the earth is not at rest." His Moorean sentence was not absurd to his students and followers because Galileo had the special desire stronger than the default desire to speak as he believed, and because the speaker and the hearers knew that the revelation of the discrepancy between his speech act and his doxastic state would not be embarrassing and would not incur a moral blame to the speaker. By contrast, his Moorean sentence was absurd to the beggar. The first conjunct triggered him to believe that Galileo believed that the earth was at rest. What he took to be Galileo's belief contradicted what the second conjunct claimed to be Galileo's belief. Also, he had no idea why Galileo spoke the first conjunct contrary to what he believed, and no idea why Galileo disclosed to some audience that what he spoke does not match up with what he believed. The lack of the relevant knowledge made Galileo's Moorean sentence mysterious to the beggar.

Note that concurrentism explains a commissive Moorean sentence as it explains an omissive Moorean sentence. In both cases, (D), (L1), and (L2) are invoked to explain why Moorean sentences are mysterious. The only difference between the explanation of an omissive Moorean sentence and the explanation of a commissive Moorean sentence is that they locate a contradiction in difference places. While the former locates it between the hearer's default belief and the speaker's second conjunct, the latter locates it between what the hearer takes to be the speaker's belief and what the second conjunct claims to be the speaker's belief.

Finally, let me apply concurrentism to a peculiar variant of a commissive Moorean sentence. The variant can be found only in commissive Moorean sentences. It is 'It's raining, but I know it's not raining.' Why is this sentence absurd? Knowledge is traditionally defined as a justified true belief in epistemology. So the second conjunct has two relevant entailments: 1. it is not raining, and 2. the speaker believes that it is not raining. First of all, the first conjunct 'It's raining' contradicts the first entailment 'It's not raining.' Furthermore, the first conjunct and the second entailment can be conjoined to form an ordinary commissive 
Moorean sentence, 'It's raining, but I believe it's not raining.' It follows that what the hearer takes to be the speaker's belief contradicts what the second conjunct claims to be the speaker's belief. Thus, two contradictions occurred in total. Moreover, the speaker goes against (L1) and (L2).

\section{Conclusion}

Concurrentism holds that we have the default desire to speak as we believe, we have the default belief that other people speak as they believe, and after we speak contrary to what we believe, we have the default desire to keep to ourselves the discrepancy between what we speak and what we believe. Concurrentism receives support from a psychological study that we suffer from cognitive dissonance when our speech act does not coincide with our belief, and that we do not usually declare to other people that our speech act does not accord with our belief. Concurrentism meshes well with evolutionary theory that the honest exchange of ideas among member of a group is beneficial for the perpetuation of the group, and the inclination to deceive competitors is beneficial for the survival and reproduction of individuals. Concurrentism can account for Moore's paradox and the diverse variants of Moorean sentences.

When the speaker says an omissive Moorean sentence, contradiction occurs between the hearer's default belief and the second conjunct of the omissive Moorean sentence. When the speaker says a commissive Moorean sentence, contradiction occurs between what the hearer takes to be the speaker's belief and what the second conjunct of the commissive Moorean sentence claims to be the speaker's belief. Moreover, the speaker goes against the linguistic inclination that we speak, ceteris paribus, in accordance with what we believe, and the linguistic inclination that we do not, ceteris paribus, disclose to other people that there is a discrepancy between what we speak and what we believe. These factors jointly give rise to Moore's paradox.

\section{References}

Audi, Robert (1994). "Dispositional Beliefs and Dispositions to Believe", Noûs 28(4): 419434.

Baker, Lyn R. (1995). Explaining Attitudes. Cambridge: Cambridge University Press.

Braithwaite, Richard. B. (1932-1933). "The Nature of Believing", Proceedings of the Aristotelian Society 33: 129-146.

Bromwich, Danielle (2010). "Clearing Conceptual Space for Cognitive Motivational Internalism", Philosophical Studies 148 (3): 343-367.

Cohen, Jonathan (1992). An Essay on Belief and Acceptance. New York: Oxford University Press.

Dennett, Daniel C. (1978). Brainstorms. Cambridge: MIT Press.

Festinger, Leon \& James Carlsmith, (1959). "Cognitive Consequences of Forced Compliance", Journal of Abnormal and Social Psychology 58: 203-201

Marcus, Ruth B. (1990). "Some Revisionary Proposals about Belief and Believing", 
Philosophy and Phenomenological Research 50: 132-153.

Moore, George (1944). "Russell's Theory of Descriptions", in Paul Schilpp (ed.), The Philosophy of Bertrand Russell. (La Salle, Ill.: Open Court) 175-225.

(1993). "Moore's Paradox", In G. E. Moore: Selected Writings. Thomas Baldwin (ed.), London: Routledge.

Park, Seungbae (2015a). “Accepting Our Best Scientific Theories”, Filosofija. Sociologija 26 (3): 218-227.

(2015b). “Against Motivational Efficacy of Beliefs", Coactivity: Philosophy. Communication 23 (1): 86-95.

Price, Henry (1969). Belief. London: Allen \& Unwin.

Quine, Willard V. O. (1960). Word and Object. Cambridge, MA: MIT Press.

Ryle, Gilbert (1949). The Concept of Mind. New York: Barnes \& Noble.

Ramsey, Frank P. (1931). The Foundations of Mathematics, and Other Logical Essays. London: Routledge \& Kegan Paul.

Schwitzgebel, Eric (2001). "In-between Believing”, The Philosophical Quarterly 51: 76-82. (2002). “A Phenomenal, Dispositional Account of Belief”, Noûs 36: 249-275.

Sober, Elliott (1993). Philosophy of Biology. Colorado: Westview Press.

Stalnaker, Robert (1984). Inquiry. Cambridge: MIT Press.

Travis, Charles (2003). Unshadowed Thought. Cambridge: Harvard University Press.

Williams, John N. (2013). "The Completeness of the Pragmatic Solution to Moore's Paradox in Belief: A Reply to Chan", Synthese 190 (12): 2457-2476. 